\title{
ANALISIS PERBANDINGAN RISIKO USAHATANI PADI SAWAH DI DESA CIJEUNGJING KECAMATAN CIJEUNGJING BERDASARKAN LUAS LAHAN
}

\author{
COMPARATIVE ANALYSIS OF RISK OF FARMING RICE IN CIJEUNGJING \\ VILLAGE, CIJEUNGJING SUB-DISTRICT BASED ON LAND AREA
}

\author{
NANDA AINI DAMAYANTI ${ }^{1}$, TRISNA INSAN NOOR ${ }^{2}$, \\ MUHAMAD NURDIN YUSUF ${ }^{1}$ \\ ${ }^{1}$ Fakultas Pertanian, Universitas Galuh \\ ${ }^{2}$ Fakultas Pertanian Universitas Padjajaran \\ *E-mail: nandaainiui27@gmail.com
}

\begin{abstract}
ABSTRAK
Usahatani selalu menghadapi sebuah ketidakpastian, dimana ketidakpastian itu akan menjadi peluang risiko. Risiko kerugian bisa terjadi pada produksi, harga dan pendapatan. Maka dari itu, penelitian ini membahas mengenai risiko produksi, harga dan pendapatan berdasarkan luas lahan di Desa Cijeungjing Kecamatan Cijeunging. Penelitian ini bertujuan untuk: (1) Menganalisis risiko produksi, risiko harga dan risiko pendapatan pada usahatani padi sawah di Desa Cijeungjing, (2) Membandingkan risiko usahatani padi menurut pengusahaan lahan oleh petani di Desa Cijeungjing. Penelitian ini menggunakan metode survey terhadap 66 petani yang diambil secara acak proporsional berdasarkan luas lahan. Teknis analisis data menggunakan koefisien variasi dan standar deviasi. Hasil penelitian menunjukkan: (1) Risiko produksi petani Desa Cijeungjing menurut nilai koefisien variasi adalah sebesar 0,62 pada MT I dan 0,58 pada MT II untuk petani berlahan sempit $(<0,25$ ha $), 0,18$ pada MT I dan 0,22 pada MT II untuk petani berlahan sedang (0,25-0,5 ha) dan 0,32 pada MT I dan 0,37 pada MT II untuk petani berlahan luas (>0,5 ha). Risiko harga petani Desa Cijeungjing menurut nilai koefisien variasi adalah sebesar 0,02 pada MT I dan 0,03 pada MT II bagi petani berlahan sempit, 0,06 pada MT I dan 0,03 pada MT II bagi petani berlahan sedang dan 0,04 pada MT I dan 0,03 pada MT II bagi petani berlahan luas. Sedangkan untuk risiko pendapatan menurut nilai koefisien variasi yaitu sebesar 0,63 pada MT I dan 0,58 pada MT II untuk petani berlahan sempit, 0,50 pada MT I dan 0,49 pada MT II untuk petani berlahan sedang serta 0,62 pada MT I dan 0,72 pada MT II untuk petani yang memiliki lahan garap luas, (2) Secara keseluruhan perbandingan risiko usahatani berdasarkan luas lahan di Desa Cijeungjing tidak jauh berbeda, dilihat dari risiko produksi dengan nilai CV $<1$ dan risiko harga dengan CV $\leq 0,5$ usahatani padi sawah di Desa Cijeungjing Kecamatan Cijeungjing termasuk ke dalam risiko yang kecil. Risiko pendapatan usahatani padi tersebut termasuk ke dalam risiko yang besar, karena nilai $\mathrm{CV}>0,5$.
\end{abstract}

Kata Kunci: padi sawah, risiko, produksi, harga, pendapatan

\section{ABSTRACT}

This research was conducted aimed to find out: (1) The production risk, price risk and income risk in lowland rice farming in Cijeungjing village, (2) Comparing the risks based on land farming area in Cijeungjing village. This research uses survey method. Sampling was done by stratified sampling with a sample of 66 rice farmers based on land area, 15 farmers with narrow land $(<0.25$ ha), 24 farmers with medium land (0.25-0.5 ha) and 27 farmers with large areas (>0.5 ha). The data analysis technique uses the coefficient of variation and standard deviation. The results showed: (1) Farmers with narrow land have a higher risk of production than farmers with medium and wide land. As for the price risk, farmers with large land area have a higher risk than farmers with small and medium land areas. And for income risk, farmers with narrow and wide land are at higher risk than farmers with medium land. Thus, the overall risk borne by farmers with wide and narrow land is higher than that of medium land farmers. 
(2) Overall the comparison of farming risks based on land area in Cijeungjing Village is not much different, seen from the production risk with $C V<1$ and the price risk with $C V \leq 0.5$ lowland rice farming in Cijeungjing Village, Cijeungjing District, is a small risk. . The income risk of rice farming is a big risk, because the CV value is $>0.5$

Keywodrs: Paddy, risks, production, price, income

\section{PENDAHULUAN}

Salah satu sektor pertanian yang diutamakan adalah pada sektor tanaman pangan seperti padi, jagung dan kedelai. Namun sampai saat ini, popularitas padi sebagai bahan makanan pokok penduduk Indonesia masih belum terkalahkan. Maka dari itu, petani dalam usahatani padi terus mencoba inovasi baru untuk memperoleh hasil yang diinginkan dan terhindar dari kerugian yang mungkin dapat terjadi.

Dalam usahatani padi, petani sering dihdapkan dengan berbagai macam ketidakpastian. Ketidakpastian tersebut bisa terjadi karena faktor alam yang mempengaruhi hasil panen dan fluktuasi harga yang mempengaruhi pendapatan petani. Dampak ketidakpastian hasil panen akan mengakibatkan produsen enggan memasuki pasar produksi (Magfira, dkk., 2020).

Ketidakpastian tersebut akan menjadi sebuah risiko atau peluang kerugian bagi petani. Risiko bisa dibedakan menjadi tiga, yaitu risiko produksi, risiko harga dan risiko pendapatan. Petani akan berusaha menghindari kegagalan dan bukan memperoleh keuntungan yang besar dengan mengambil risiko (Sriyadi, 2010).

Dari segi produksi, Desa Cijeungjing merupakan penghasil produksi padi terbesar di Kecamatan Cijeungjing dengan rata-rata 7 ton/ha. Dengan produksi yang tinggi, luas lahan Desa Cijeungjing hanya berkisar 45,50 hektar saja, lebih kecil dibandingkan dengan desa lain di Kecamatan Cijeungjing. Fakta di lapangan menunjukkan bahwa luas kepemilikan lahan petani padi sawah Desa Cijeungjing adalah rata-rata $>0,5$ hektar.

Untuk mengetahui perbandingan risiko usahatani padi sawah di Desa Cijeungjing berdasarkan luas lahan, penulis mengambil skala pembagian lahan seperti dalam penelitian Prihtanti (2014), lahan sempit yaitu $<0,25$ ha, lahan sedang yaitu 0,25-0,5 ha, dan lahan luas >0,5 ha.

Berdasarkan uraian tersebut, maka penelitian ini dilaksanakan dengan tujuan menganalisis risiko produksi, risiko harga dan risiko pendapatan petani padi sawah di Desa Cijeungjing. Serta membandingkan risiko usahatani padi menurut pengusahaan lahan oleh petani di Desa Cijeungjing. 


\section{METODE PENELITIAN}

Penelitian dilaksanakan dengan menggunakan metode survey. Dimana data yang dihasilkan dari sampel merupakan perwakilan populasi yang diambil dan bertujuan memberikan gambaran tertentu pada populasi yang ada. Data yang digunakan terdiri atas data primer hasil kuisioner dan sekunder hasil dari penelitian terdahulu juga instansi terkait. Data yang diambil merupakan data dari dua kali musim tanam tahun 2020 di Desa Cijeungjing.

\section{Penarikan Sampel}

Sampel lokasi diambil menggunakan purposive sampling, menurut Pasaribu (1983), purposive sampling adalah memilih sampel secara sengaja dengan pertimbangan-pertimbangan khusus atau berdasarkan kriteria tertentu yang dimiliki sampel tersebut. Sedangkan sampel responden diambil secara stratified sampling, dimana teknik tersebut adalah cara penarikan sampel untuk populasi yang memiliki karakteristik heterogen atau karakteristik yang dimiliki populasi bervariasi (Prasetyo dan Jannah, 2005). Responden dikelompokkan menjadi tiga kategori berdasarkan luas lahan. Lahan sempit $(<0,25$ ha) 15 orang, lahan sedang
(0,25-0,5 ha) 24 orang dan lahan luas ( $>0,5$ ha) 27 orang.

\section{Rancangan Analisis Data}

Setelah ditabulasi, data diolah menggunakan alat analisis data sebagai berikut :

\section{Analisis Biaya \\ Dengan menghitung berbagai biaya} yang dikeluarkan petani selama proses produksi. Dimana biaya total tersebut adalah penjumlahan biaya tetap dan biaya variabel. Menurut Suratiyah (2015), biaya total dituliskan sebagai berikut :

$\mathrm{TC}=\mathrm{TFC}+\mathrm{TVC}$

Keterangan :

TC : Total cost (biaya total)

TFC : Total fixed cost (biaya tetap total)

TVC : Total variabel cost (biaya variabel total)

2. Analisis Penerimaan

Dapat dirumuskan sebagai berikut (Suratiyah, 2015) :

$\mathrm{TR}=\mathrm{P} \times \mathrm{Q}$

Keterangan :

TR : Total revenue/total penerimaan (Rp)

$\mathrm{P} \quad$ : Price/harga hasil produksi (Rp)

Q : Quantity/hasil produksi (kg)

3. Analisis Pendapatan 
Didapatkan dari pengurangan antara penerimaan dengan biaya total dan dapat dirumuskan sebagai berikut (Suratiyah, 2015) :

$\pi=\mathrm{TR}-\mathrm{TC}$

Keterangan :

$\pi \quad$ : Profit/Pendapatan (Rp)

TR : Total revenue/total penerimaan (Rp)

TC : Total cost (biaya total)

4. Analisis Risiko

Terdiri dari risiko produksi, risiko harga dan risiko pendapatan. Risiko dapat dihitung menggunakan koefisien variasi dengan simpangan baku, dan batas bawah sebagai nilai terendah yang mungkin didapatkan oleh petani baik dalam produksi, harga maupun pendapatan. (Snedecor and Cochran, 1973 ; Algifari, 1999) yang dapat diformulasikan sebagai berikut :

$\mathrm{CV}=\sigma / \bar{X} \times 100 \%$

Rumus simpangan baku dapat dilihat sebagai berikut :

$\sigma=\frac{\sqrt{\Sigma(x-x)^{2}}}{n-1}$

Keterangan :

$\mathrm{CV}$ : Koefisien variasi

$\sigma \quad$ : Standar deviasi

cv: : Nilai rata-rata $\mathrm{X}$ faktor tertentu (produksi/harga/pendapatan)

n : Jumlah sampel
Rumus batas bawah produksi, harga dan pendapatan dapat dilihat sebagai berikut :

$C V=\frac{\sigma}{\bar{X}}$

Keterangan :

$\mathrm{CV}$ : Koefisien variasi

$\sigma \quad$ : Standar deviasi

$\underset{c}{c}:$ : $\quad$ Nilai rata-rata $X$ faktor tertentu (produksi/harga/pendapatan)

Kriteria yang dipakai untuk risiko produksi, harga dan pendapatan adalah sebagai berikut (Magfira, dkk., 2020) :

1) Risiko produksi, jika nilai $\mathrm{CV} \leq 1$ maka usahatani yang dianalisis memiliki risiko kecil. Nilai $\mathrm{CV} \geq 1$ maka usahatani yang dianalisis memiliki risiko besar. Batas bawah produksi, jika $\mathrm{L}=0$ atau $\mathrm{L} \leq 0$, maka petani mengalami kerugian. Jika $\mathrm{L} \geq 0$, maka petani tidak mengalami kerugian.

2) Risiko harga, jika nilai $\mathrm{CV}>0,5$ maka nilai $\mathrm{L}<0$. Jika niai $\mathrm{CV} \leq 0,5$ maka nilai $\mathrm{L} \geq 0$. Dengan demikian, jika nilai $\mathrm{CV}>0,5$ maka risiko harga pada usahatani padi yang akan ditanggung petani semakin besar dan menanggung kerugian sebesar L. Nilai $\mathrm{CV} \leq 0,5$ maka petani akan untung dengan harga L.

3) Risiko pendapatan, jika nilai $\mathrm{CV}>0,5$ maka nilai $\mathrm{L}<0$. Jika nilai $\mathrm{CV} \leq 0,5$ maka nilai $L \geq 0$. Dengan demikian, jika 
nilai $\mathrm{CV}>0,5$ maka risiko pendapatan usahatani padi yang ditanggung petani semakin besar dan menanggung kerugian sebesar L. Nilai $\mathrm{CV} \leq 0,5$ maka petani akan untung dengan pendapatan sebesar L.

\section{HASIL DAN PEMBAHASAN}

\section{Karakteristik Responden}

Karakteristik responden meliputi umur, pengalaman bertani, pendidikan, jumlah tanggungan keluarga, dan luas lahan garapan petani dapat dilihat dari Tabel 1.

\section{Tabel 1. Karakteristik Responden}

\begin{tabular}{|c|c|c|c|}
\hline No & Uraian & Jumlah & Persentase (\%) \\
\hline 1 & $\begin{array}{l}\text { Umur Responden (Tahun) } \\
\text { a. } 30-45 \text { Tahun } \\
\text { b. } 46-61 \text { Tahun } \\
\text { c. }>61 \text { Tahun } \\
\text { Jumlah }\end{array}$ & $\begin{array}{l}11 \\
27 \\
23 \\
66 \\
\end{array}$ & $\begin{array}{c}16,67 \\
40,91 \\
42,42 \\
\mathbf{1 0 0 , 0 0}\end{array}$ \\
\hline 2 & $\begin{array}{l}\text { Pengalaman Bertani (Tahun) } \\
\text { a. } 5-15 \text { Tahun } \\
\text { b. } 16-26 \text { Tahun } \\
\text { c. > } 26 \text { Tahun } \\
\text { Jumlah }\end{array}$ & $\begin{array}{l}26 \\
16 \\
24 \\
66\end{array}$ & $\begin{array}{c}39,39 \\
24,24 \\
36,36 \\
\mathbf{1 0 0 , 0 0}\end{array}$ \\
\hline 3 & $\begin{array}{l}\text { Tingkat Pendidikan } \\
\text { a. Tamat SD } \\
\text { b. Tamat SMP } \\
\text { c. Tamat SMA } \\
\text { d. Tamat D3/S1 } \\
\text { Jumlah }\end{array}$ & $\begin{array}{c}33 \\
17 \\
10 \\
6 \\
66\end{array}$ & $\begin{array}{c}50,00 \\
25,76 \\
15,15 \\
9,09 \\
\mathbf{1 0 0 , 0 0}\end{array}$ \\
\hline 4 & $\begin{array}{l}\text { Jumlah Tanggungan Keluarga (Orang) } \\
\text { a. } 0 \\
\text { b. } 1-3 \\
\text { c. }>3 \\
\text { Jumlah }\end{array}$ & $\begin{array}{c}3 \\
57 \\
6 \\
66\end{array}$ & $\begin{array}{c}4,55 \\
86,36 \\
9,09 \\
\mathbf{1 0 0 , 0 0}\end{array}$ \\
\hline 5 & $\begin{array}{l}\text { Luas Lahan Garapan Padi }(\mathrm{Ha}) \\
\text { a. }<0,25 \\
\text { b. } 0,25-0,5 \\
\text { c. }>0,5 \\
\text { Jumlah }\end{array}$ & $\begin{array}{l}15 \\
24 \\
27 \\
66\end{array}$ & $\begin{array}{c}22,73 \\
36,36 \\
40,91 \\
\mathbf{1 0 0 , 0 0}\end{array}$ \\
\hline
\end{tabular}

Sumber: Analisis Data Primer, 2020

Tabel 1 menunjukkan bahwa dominan responden berumur $>61$ tahun dimana usia tersebut sudah dikatakan tidak produktif. Hal ini disebabkan oleh banyaknya masyarakat Desa Cijeungjing yang berusia produktif malah bekerja sebagai karyawan swasta di dalam maupun luar kota. 
Sebagian besar responden memiliki pengalaman yang masih kurang berkisar antara 5-15 tahun. Pengalaman berusahatani dapat mempengaruhi bagaimana cara pengambilan keputusan petani saat menghadapi suatu masalah, dan mengurangi risiko-risiko usahatani yang dapat terjadi.

Sebagian besar responden memiliki tingkat pendidikan setingkat Sekolah Dasar (SD) yaitu sebanyak 33 orang atau (50\%) yang menunjukkan rendahnya tingkat pendidikan dari responden. Hal ini akan mempengaruhi tingkat adaptasi serta inovasi dari pertumbuhan dan perkembangan teknologi pertanian.

Responden yang memiliki jumlah tanggungan keluarga 1-3 orang sebanyak 57 petani $(86,36 \%)$, dan yang memiliki jumlah tanggungan keluarga $>3$ orang sebanyak 6 petani $(9,09 \%)$. Semakin banyak jumlah tanggungan keluarga, maka petani juga akan semakin besar mengeluarkan biaya untuk kebutuhan hidupnya. Namun dalam tenaga kerja, semakin banyak jumlah tanggungan keluarga maka semakin banyak juga jumlah tenaga kerja dalam kerluarga yang bisa menekan biaya untuk pengeluaran tenaga kerja.

Sebagian besar responden memiliki lahan seluas >0,5 hektar. Semakin luas lahan yang digarap, maka akan semakin besar biaya yang dikeluarkan, begitu juga dengan produksi yang didapatkan lebih banyak. Kempemilikan lahan luas (>0,5 ha) rata-rata adalah lahan sewa.

\section{Analisis Biaya, Penerimaan dan Pendapatan}

Biaya total, produksi, harga jual, penerimaan dan pendapatan per musim tanam per luas lahan dapat dilihat pada Tabel 2. 
Tabel 2. Rata-rata Biaya, Produksi, Harga, Penerimaan dan Pendapatan Per Musim Tanam

\begin{tabular}{lccc}
\hline \multicolumn{1}{c}{$\begin{array}{c}\text { Jenis } \\
\text { Biaya }(\mathbf{R p})\end{array}$} & $\begin{array}{c}\text { Lahan } \\
\text { Sempit } \\
(<\mathbf{0 , 2 5} \text { ha) })\end{array}$ & $\begin{array}{c}\text { Lahan } \\
\text { Sedang } \\
(\mathbf{0 , 2 5 - 0 , 5} \text { ha })\end{array}$ & $\begin{array}{c}\text { Lahan } \\
\text { Luas } \\
(>\mathbf{0 , 5} \text { ha })\end{array}$ \\
\hline 1. Biaya Total & $356.719,11$ & $2.530 .227,08$ & $3.941 .370,50$ \\
Biaya Tetap & $562.700,00$ & $1.574 .333,33$ & $3.084 .018,52$ \\
Biaya Variabel & $\mathbf{9 1 9 . 4 1 9 , 1 1}$ & $\mathbf{4 . 1 0 4 . 6 1 0 , 4 1}$ & $\mathbf{7 . 0 2 5 . 3 8 9 , 0 2}$ \\
Biaya Total & & &
\end{tabular}

2. Penerimaan

a. Musim Tanam I
a) Produksi (kg)
574,67
$1.834,58$
$3.692,07$
b) Harga $(\mathrm{Rp} / \mathrm{kg})$
$4.780,00$
$4.575,00$
$4.581,48$

b. Musim Tanam II
a) Produksi (kg)
491,33
$1.545,83$
$3.050,74$
b) Harga $(\mathrm{Rp} / \mathrm{kg})$
$5.020,00$
$5.125,00$
$5.125,93$

Penerimaan Total

\begin{tabular}{llll|} 
a. Musim Tanam I & $2.753 .200,00$ & $\mathbf{8 . 4 2 4 . 9 1 6 , 6 7}$ & $\mathbf{1 6 . 9 2 6 . 3 9 2 , 5 9}$ \\
b. Musim Tanam II & $\mathbf{2 . 4 8 3 . 3 3 3 , 3 3}$ & $\mathbf{7 . 9 0 8 . 5 4 1 , 6 7}$ & $\mathbf{1 5 . 6 0 3 . 8 5 1 , 8 5}$ \\
\hline
\end{tabular}

3. Pendapatan

\begin{tabular}{llll|} 
a. Musim Tanam I & $1.833 .780,89$ & $4.320 .306,25$ & $9.901 .003,57$ \\
b. Musim Tanam II & $1.563 .914,22$ & $3.803 .931,25$ & $\mathbf{8 . 5 7 8 . 4 6 2 , 8 3}$ \\
\hline
\end{tabular}

Sumber: Analisis Data Primer, 2020

Tabel 2 menunjukkan bahwa semakin besar lahan yang digarap, maka akan semakin besar pula biaya yang dikeluarkan. Selain biaya, penerimaan, hasil produksi dan pendapatan juga akan lebih besar jika petani memiliki luas lahan garap $>0,5$ ha.

\section{Analisis Risiko Usahatani Padi}

Perbandingan risiko usahatani padi sawah berdasarkan luas lahan di Desa Cijeungjing Kecamatan Cijeungjing dapat dilihat dari Tabel 3. Batas bawah produksi, harga dan pendapatan dapat dilihat dari Tabel 4.

Tabel 3. Perbandingan Risiko Usahatani Padi Sawah Berdasarkan Luas Lahan

\begin{tabular}{lcccccc}
\hline \multirow{2}{*}{$\begin{array}{c}\text { Risiko } \\
\text { Usahatani }\end{array}$} & \multicolumn{2}{c}{$\begin{array}{c}\text { Sempit } \\
(<\mathbf{0 , 2 5} \text { ha) }\end{array}$} & \multicolumn{2}{c}{$\begin{array}{c}\text { Sedang Lahan } \\
(\mathbf{0 , 2 5 - 0 , 5} \text { ha) }\end{array}$} & \multicolumn{2}{c}{$\begin{array}{c}\text { Luas } \\
(>\mathbf{0 , 5} \text { ha })\end{array}$} \\
\cline { 2 - 7 } & MT I & MT II & MT I & MT II & MT I & MT II \\
\hline Produksi & 0,62 & 0,58 & 0,18 & 0,22 & 0,32 & 0,34 \\
Harga & 0,02 & 0,03 & 0,06 & 0,03 & 0,04 & 0,03 \\
Pendapatan & 0.63 & 0,58 & 0,50 & 0,49 & 0,62 & 0,72 \\
\hline
\end{tabular}

Sumber: Analisis Data Primer, 2020 
Dari tabel tersebut, maka dapat dilihat bahwa semakin sempit lahan yang digarap, maka semakin tinggi pula risiko produksi yang dihadapi. Jika dilihat dari nilai koefisien variasi musim tanam satu dan dua, maka petani berlahan sempit memiliki risiko yang lebih tinggi dibandingkan dengan petani berlahan sedang dan luas. Semakin besar nilai standar deviasi maka semakin besar penyimpangan yang menyebabkan risiko semakin besar dan demikian juga sebaliknya (Rama, dkk., 2016).

Risiko harga pada produksi pertanian disebabkan oleh harga pasar yang tidak dapat dikuasai petani (Magfira, 2020). Rendahnya risiko harga pada petani berlahan sempit disebabkan karena harga jual yang diterima petani relatif lebih tinggi daripada petani berlahan sedang dan luas. Harga yang lebih tinggi adalah karena petani berlahan sempit lebih memilih untuk bergabung dengan kelompok tani saat menjual hasil poduksinya dengan harga yang relatif sama. Pada petani berlahan sedang dan luas, mereka menjual hasil produksinya pada tengkulak lokal sehingga harga jual yang diterimapun lebih rendah.

Tingginya risiko pendapatan pada petani berlahan sempit tidak lain disebabkan oleh rendahnya produksi, lahan garap yang sempit, juga hasil produksi yang sebagian tidak dijual. Petani berlahan sempit lebih memilih mengkonsumsi hasil produksi tersebut atau menyimpannya sebagai cadangan untuk bahan pangan mereka sendiri untuk menghindari risiko. Rendahnya pendapatan juga mengakibatkan petani berlahan sempit tidak memiliki pilihan lain selain mengkonsumsi hasil produksi dari usahataninya sendiri, serta didukung oleh turunnya produksi saat kemarau.

Sedangkan petani berlahan luas memiliki risiko lebih tinggi pada musim tanam dua yang disebabkan oleh penurunan produksi secara drastis, lahan garap sebagian ditanami palawija ataupun dibiarkan saja. Hal ini sejalan dengan hasil penelitian yang dilakukan oleh Prihtanti (2014) yaitu, semakin tinggi luas lahan diusahakan, semakin kecil risiko yang dihadapi dilihat dari koefisien variasi pendapatan

\section{KESIMPULAN DAN SARAN}

\section{Kesimpulan}

Risiko produksi petani Desa Cijeungjing menurut nilai koefisien variasi adalah sebesar 0,62 pada MT I dan 0,58 pada MT II untuk petani berlahan sempit ( $<0,25$ ha), 0,18 pada MT I dan 0,22 pada MT II untuk petani berlahan sedang $(0,25$ - 
0,5 ha) dan 0,32 pada MT I dan 0,37 pada MT II untuk petani berlahan luas (>0,5 ha). Risiko harga petani Desa Cijeungjing menurut nilai koefisien variasi adalah sebesar 0,02 pada MT I dan 0,03 pada MT II bagi petani berlahan sempit, 0,06 pada MT I dan 0,03 pada MT II bagi petani berlahan sedang dan 0,04 pada MT I dan 0,03 pada MT II bagi petani berlahan luas. Sedangkan untuk risiko pendapatan menurut nilai koefisien variasi yaitu sebesar 0,63 pada MT I dan 0,58 pada MT II untuk petani berlahan sempit, 0,50 pada MT I dan 0,49 pada MT II untuk petani berlahan sedang serta 0,62 pada MT I dan 0,72 pada MT II untuk petani yang memiliki lahan garap luas.

Secara keseluruhan kategori luas lahan, dilihat dari risiko produksi dengan nilai $\mathrm{CV}<1$ dan risiko harga dengan nilai $\mathrm{CV} \leq 0,5$ usahatani padi sawah di Desa Cijeungjing Kecamatan Cijeungjing termasuk ke dalam risiko yang kecil. Risiko pendapatan usahatani padi tersebut termasuk ke dalam risiko yang besar, karena nilai $\mathrm{CV}>0,5$.

\section{Saran}

Petani diharapkan untuk mampu mengatasi risiko-risiko usahataninya dengan melaksanakan anjuran dari pemerintah serta lebih bijak dalam mengambil keputusan.

Diperlukannya penyuluhan lebih lanjut tentang musim tanam padi dan cara untuk mengatasi risiko usahatani padi serta peningkatan kemampuan atau keterampilan petani Desa Cijeungjing.

Pemerintah diharapkan agar bisa membuat sebuah saluran irigasi teknis untuk menghindari penurunan produksi akibat musim kemarau.

Perlunya penelitian lebih lanjut mengenai risiko usahatani selain dari berbagai pengusahaan lahan di Desa Cijeungjing.

\section{DAFTAR PUSTAKA}

Magfira, M. Noor, T.I. dan Hakim, D.L. 2020. Analisis Perbandingan Risiko Usahatani Padi Sawah dan Padi Rawa. Jurnal Ilmiah Mahasiswa Agroinfo Galuh, 7(1): 14-27.

Pasaribu, I.L dan Simanjuntak, B. 1983. Proses Belajar Mengajar. Bandung : Tarsito.

Prasetyo, B. dan Jannah, L.M. 2005 Metode Penelitian Kuantitatif. Jakarta : Rajagrafindo Perkasa. Hal: 130.

Prihtanti, T.M. 2014. Analisis Risiko Berbagai Luas Pengusahaan Lahan pada Usahatani Padi Organik dan Konvensional. AGRIC, $26(1 \& 2)$ : 29-36.

Rama, Rofinus. Nurliza. dan Dolorosa, Eva. 2016. Analisis Risiko Produksi Usahatani Padi Lahan Basah dan Kering di Kabupaten 
Melawi. Jurnal Social Economic of Agriculture, 5(1):73-88.

Snedecor, George Waddel, and WG.Cochran. 1973. Statistical Method. Iowa State.

Sriyadi. 2010. Risiko Produksi dan Keefisienan Relatif Usahatani
Bawang Putih di Kabupaten Karanganyar. Jurnal Pembangunan Pedesaan, 10(2): 69-76.

Suratiyah, K. 2015. Ilmu Usahatani. Edisi Revisi. Jakarta : Penebar Swadaya. 